\title{
A Mini-Review on the Epidemiology of Canine Parvovirus in China
}

\author{
Shanshan Qi ${ }^{\dagger}$, Jianjun Zhao ${ }^{+}$, Donghua Guo and Dongbo Sun* \\ College of Animal Science and Veterinary Medicine, Heilongjiang Bayi Agricultural University, Daqing, China
}

Canine viral diarrhea is a severe disease in dogs worldwide. The role of canine parvovirus (CPV) in canine viral diarrhea is a common health problem in dogs, attracting major concern from veterinarians and dog owners across China. In this mini-review, we summarize the CPV epidemiology in China, including its origin, prevalence, coinfection, and the genetic evolution of the virus. The review reveals the correlation between CPV-2 infection and seasonality, a dog's age/gender/breed/vaccination; that CPV-2 is the main causative agent of canine diarrhea in Northeast China and that coinfection with other pathogens is a common occurrence; the predominant CPV epidemic strains were the new CPV-2a, and CPV-2c has shown significant growth trends since 2010.

OPEN ACCESS

Edited by:

Lester J. Perez,

University of Illinois at

Urbana-Champaign, United States

Reviewed by:

Gregorio Iraola,

Institut Pasteur de

Montevideo, Uruguay

Selwyn Arlington Headley,

State University of Londrina, Brazil

*Correspondence:

Dongbo Sun

dongbosun@126.com

tThese authors have contributed equally to this work

Specialty section:

This article was submitted to Veterinary Infectious Diseases, a section of the journal

Frontiers in Veterinary Science

Received: 05 October 2019

Accepted: 07 January 2020

Published: 20 February 2020

Citation:

Qi S, Zhao J, Guo D and Sun D (2020)

A Mini-Review on the Epidemiology of

Canine Parvovirus in China.

Front. Vet. Sci. 7:5.

doi: 10.3389/fvets.2020.00005
This mini-review will provide valuable information for CPV infections across China and other countries.

Keywords: canine parvovirus, epidemiology, prevalence, coinfection, phylogenetic analysis

\section{INTRODUCTION}

In canine disease, viral diarrhea has a high incidence because of etiology complexity, which causes serious harm to the canine industry and dogs. At present, several viral pathogens are related to canine diarrhea in China, including canine parvovirus $(\mathrm{CPV})(1,2)$, canine coronavirus $(\mathrm{CCoV})$, canine bocavirus, canine kobuviruses (CaKVs), and canine distemper virus (CDV). $\mathrm{CPV}$ is an important cause of mortality and morbidity in dogs, especially puppies, in China and the rest of the world (3-5). Variation, recombination, and coinfection have been shown to aggravate clinical symptoms and challenge the prevention and control of CPV infections (6-9). Dogs that become infected by CPV show illness within 3-7 days, presenting with severe gastroenteritis, lethargy, vomiting, fever, and diarrhea (usually bloody) (10-12).

CPV belongs to the genus Parvovirus, family Parvoviridae, and causes a highly contagious and fatal disease in dogs (1). The original viral strain, designated as CPV-2 to distinguish it from CPV1 which is also known as canine minute virus and was believed to be non-pathogenic until 1992 (13). CPV-2 is a non-enveloped DNA virus with a linear single-stranded DNA genome (5.2 kb), containing two major open reading frames (ORFs). One ORF encodes the two non-structural proteins (NS1 and NS2), and the other encodes the two capsid proteins (VP1 and VP2) (14). The VP2 protein of CPV-2 is known to affect antigenic properties, playing important roles in controlling viral host ranges and tissue tropisms (15-17).

The main method for controlling the virus in domestic animals is by vaccination, antibody therapy, and traditional Chinese medicine therapy $(18,19)$. However, the virus is widely distributed in nature, and the morbidity and mortality of CPV-2-infected animals remain high (20). Furthermore, because of vaccine formulations, a dramatic increase in the number of dog or other factors potentially promote the spread of different CPV-2 antigenic variants, increasing disease complexity (21-23). In previous studies, researchers have investigated CPV-2 genetic evolution 
(5, 24-27), providing important reference information for the prevention and control of the CPV-2 infections. However, the molecular epidemiology and genetic diversity of CPV-2 need to be updated in China. In this review, we have summarized contemporary data on the progression of CPV-2 epidemiology in China, including the virus origin, prevalence, coinfection, and evolution. The aim is to unravel CPV-2 epidemiology and provide new information on virus infections, not only for Chinese dogs and their owners but also for all dog owners across the world.

\section{THE ORIGIN OF CPV-2 IN CHINA}

In 1978, CPV was first reported as a viral diarrhea pathogen in canine populations in the United States (2) and other countries (28). Since 1970, suspected CPV-2 infections have repeatedly caused acute diarrhea disease in police dogs in East, Southwest, and Northeast China (29). However, due to a lack of diagnostic methods, the causative agents of this disease were not confirmed as CPV-2 until 1982 (30). In 1983, a series of diagnostic methods, including hemagglutination tests, hemagglutination inhibition tests, electron microscopy, and immunoelectron microscopy confirmed that CPV-2 was the causative agent of diarrhea in dogs $(29,31,32)$. Since then, comprehensive CPV2 epidemiological, diagnostic, and vaccine development research has continued across China (33-35). Subsequently, CPV-2 has gradually become one of the most important pathogens of viral diarrhea in Chinese canine populations, with a high prevalence.

\section{THE PREVALENCE OF CPV-2 IN CHINA}

\section{Morbidity and Mortality of CPV-2 in China}

Since CPV-2 was confirmed in China, the disease has shown a local endemic tendency, with different morbidities and mortalities. In the 1970s, CPV-2 morbidity varied between 30 and $40 \%$, with a mortality rate of over $10 \%$ (29). In the 1980 s, CPV2 incidence varied between 41.61 and $100 \%$, and the mortality rate varied from 3.1 to $60 \%(33,36)$. The positive rate of expression of CPV-2 antibody varied from 48.92 to $100 \%$ in the 1980s $(34,37)$. From the 1990s to the current era, CPV-2 incidence in clinical animal hospitals has varied between 3.90 and $95.8 \%$, and the mortality rate has varied between 20.17 and $73.47 \%$ (38-47). The positive rate of expression of CPV-2 antibody varied from 40.9 to $100 \%(48,49)$ (Figure 1). Since the discovery of the virus, the overall morbidity has been reduced and antibody levels to CPV-2 have remained stable; however, animal mortality rates have significantly increased, suggesting that the virus is significantly more virulent and more destructive to the animal, may be due in large part to emerging CPV antigenic variants (Figure 1).

\section{Seasonality of CPV-2 Infections}

Depending on seasonal variation, the occurrence of CPV-2 is a year-round phenomenon. In spring (March to May), CPV-2 incidences vary from 9.26 to $40.52 \%$, whereas in summer (June to August), incidences vary from 7.70 to $52.22 \%$; in the autumn (September to November), incidences vary from 5.48 to $33.06 \%$, and in the winter (December to February), they vary from 14.80 to $33.04 \%(43,45,50-54)$ (Figure 2). The proportion of CPV-2 incidences from January to December varied from 1.9 to $31.43 \%$, 2.8 to $33.33 \%, 5.6$ to $38.29 \%, 11.48$ to $31.71 \%, 8.84$ to $27.91 \%$, 2.8 to $20.69 \%, 1.7$ to $16.13 \%, 1.9$ to $16.27 \%, 4.26$ to $18.70 \%, 5.86$ to $27.78 \%, 4.10$ to $35.56 \%$, and 2.20 to $32.88 \%$, respectively ( 39 , 41, 47, 55, 56) (Figure 3). As can be showed from Figures 2, 3, the morbidities in spring, late autumn, and early winter were relatively higher than those in other seasons, which in turn may have been related to large seasonal diurnal temperature differences and changeable climates during these seasons. Several studies have reported that CPV-2 infection rates were higher in spring and autumn (8). Such findings were possibly due to the increased frequency of outdoor activities for dogs and humans, where dogs were more likely to contact with viral pathogens, making them susceptible to disease $(41,42)$. In general, CPV2 can cause infections throughout the year and variations in morbidity according to the season in different regions of China, in which the infection is more serious in the spring, late autumn, and early winter.

\section{Correlations Between a Dog's Age and CPV-2 Infections}

Dogs of all ages can be infected by CPV-2. The positive rate of CPV-2 varies by dogs ages. For 1 month old, the positive
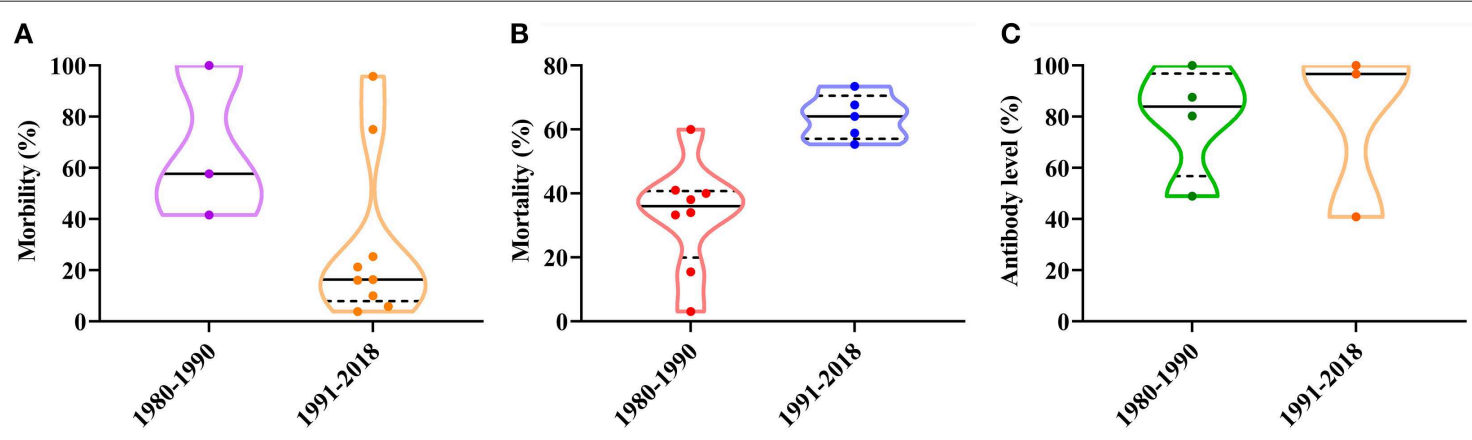

FIGURE 1 | (A) Temporal distribution analysis of the morbidity of canine parvovirus (CPV) in China. (B) Temporal distribution analysis of the mortality of CPV in China. (C) Temporal distribution analysis of antibody levels of CPV in China. 


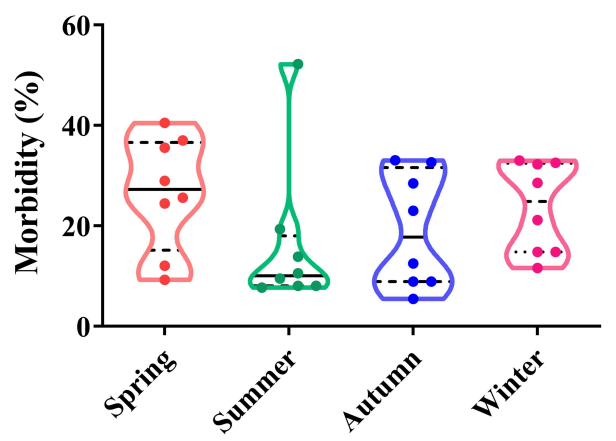

FIGURE 2 | Seasonal correlation analysis of canine parvovirus (CPV) infections in China.

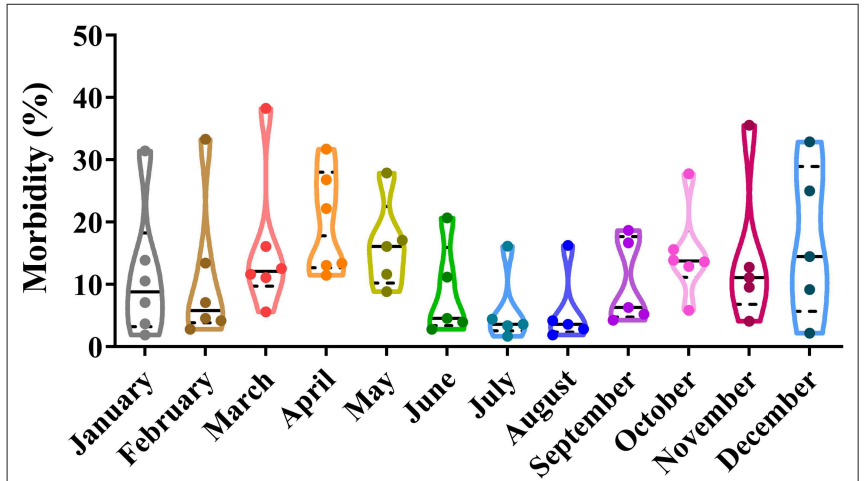

FIGURE 3 | Monthly correlation analysis of canine parvovirus (CPV) infections in China.

proportion varies from 5.40 to $9.93 \%$; for 2 months old, it varies from 10.11 to $38.40 \%$; for 3 months old, it varies from 11.26 to $23.08 \%$; for 4 months old, it varies from 8.21 to $16.38 \%$; between 5 months and 1 year, it varies from 2.55 to $7.65 \%$; from 1 to 2 years, it varies from 0.00 to $18.03 \%$; and over 2 years old, it varies from 0.00 to $11.20 \%(39,41,42,46,47,50,55-60)$ (Figure 4). The figure demonstrated that higher positive rates of CPV-2 were found in animals ranging from 2 to 4 months old, which was similar to the observations by Cavalli et al. (59) and Geng et al. (60). The low morbidity in dogs aged $<1$ month old most likely resulted from acquired maternal antibody, while the low morbidity in dogs aged more than 4 months old most likely resulted from the development of adaptive immune responses; dogs at 2-4 months account for a high CPV-2 incidence, which may reflect decreases in dog-specific maternal antibody levels $(8,56,61,62)$. Adult dogs are relatively resistant to the virus; this may be related to increased vaccination rates and developed immune functions, thereby reducing disease incidence (53). In conclusion, there are significant differences in CPV-2 susceptibilities at different dog ages, with a negative correlation between the incidence of CPV-2 and dog over 2 months old (Figure 4).

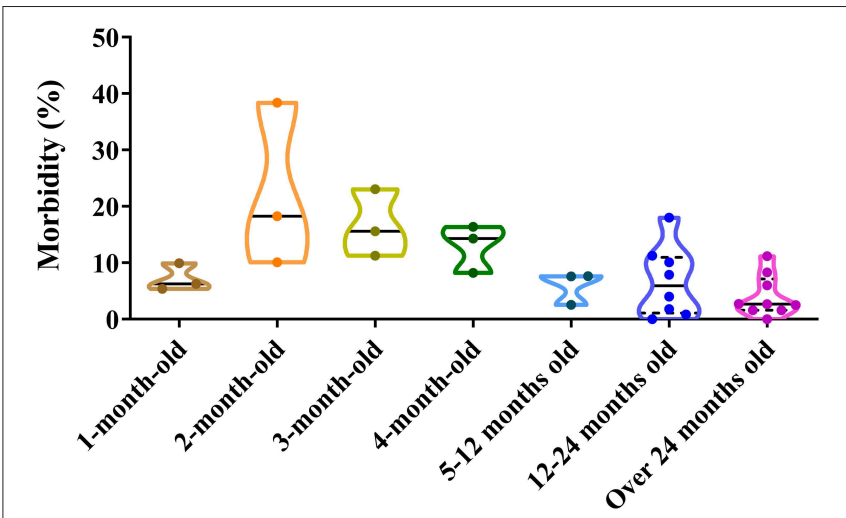

FIGURE 4 | Correlation between a dog's age and canine parvovirus (CPV) infection in China.

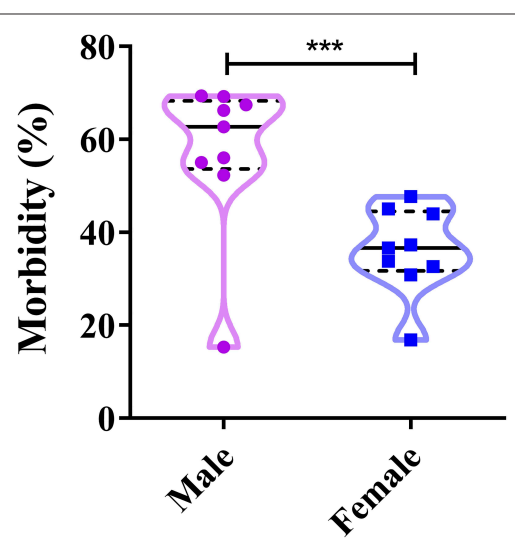

FIGURE 5 | Correlation between a dog's gender and canine parvovirus (CPV) infection in China. ${ }^{* \star *} P<0.05$.

\section{Correlations Between a Dog's Gender and CPV-2 Infections}

The proportion of CPV-positive male dogs varies between 15.29 and $69.20 \%$, whereas that of positive female dogs varies between 16.80 and $47.7 \%(39,41-43,48,51,52,54)$ (Figure 5). The figure suggests that both male and female dogs can be infected with CPV-2; however, male dogs account for the higher disease prevalence $(8,63)$. This appears to be related to the dog market in China; most pet stores predominantly sell male dogs, as the breeding number of male dogs is higher than that for female dogs, which leads to higher infection rates in these male dogs $(40,58)$. Nevertheless, the prevalence of CPV-2 in dogs shows significant gender variation, usually occurring more in male dogs than female dogs (Figure 5).

\section{Correlations Between the Breed of Dog and CPV-2 Infections}

In total, different dog breeds can be infected by CPV-2 $(45,60)$. The proportion of CPV-2 positive purebreds, hybrids, and native dogs varies from 12.15 to $91.5 \%, 6.46$ to $29.40 \%$, and 9.90 to 


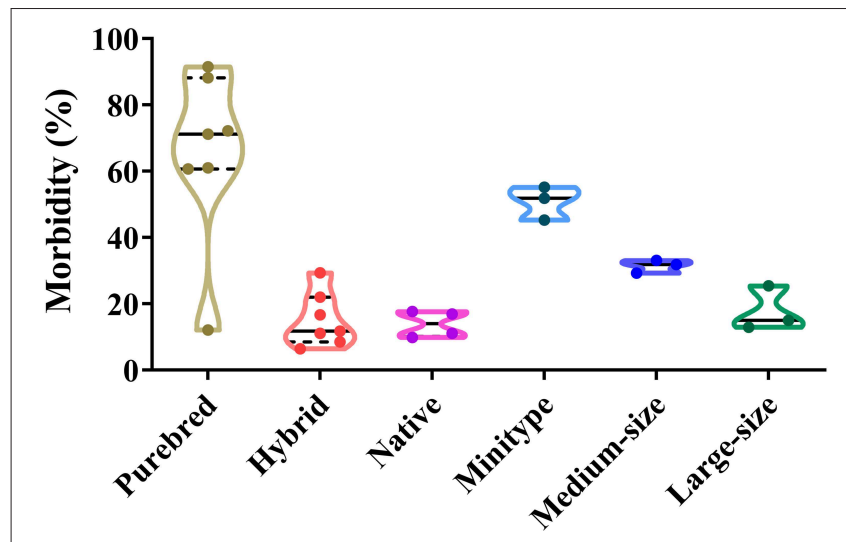

FIGURE 6 | Correlation between dog breeds and canine parvovirus (CPV) infection in China.

$17.7 \%$, respectively. The proportion of CPV-2 positive minitypes, medium-sized, and large-sized dogs varies from 45.26 to $55.18 \%, 29.31$ to $33.10 \%$, and 12.92 to $25.43 \%$, respectively ( 39 , $42,45,47,50-52,58$ ) (Figure 6). Among confirmed CPV-2 cases, the incidence of disease in purebred dogs was the highest due to increasing numbers of purebred dogs being sought by owners, which was far higher than hybrids and native dogs (Figure 6). In addition, hybrids and native dogs have greater resistance to CPV, and importantly, they were able to better adapt to local climates and environments (58). The figure showed that all dog breeds are susceptible to the virus; however, hybrids and native dogs are less susceptible than many purebreds, which should be investigated in future studies.

\section{Correlation Between Dog Vaccination and CPV-2 Infection}

The proportion of CPV-2-positive unvaccinated dogs varies between 32.63 and $84.98 \%$, whereas CPV-2 positive vaccinated dogs (vaccinated at least once) varies between 15.02 and $48.42 \%$ (Figure 7). Both vaccinated and unvaccinated dogs can be affected by CPV-2 (60). The positive rates of CPV in unvaccinated dogs were significantly higher than those in vaccinated animals $(41-43,47,50,55,56,58,60)$. The above studies show that vaccination is vitally important for the prevention and control of CPV-2. In China, insufficient attention is often paid to dogs, and therefore, individuals have not yet realized the importance of immunizing their pets. This in turn leads to a large proportion of unimmunized sick dogs. In conclusion, the key to preventing canine parvovirus is to establish a timely and functional immune response.

\section{Recovery Rates of CPV-2 Affected Dogs}

Fluid replacement, systemic antibiotic administration, antinausea medicines, antidiarrhea medicines, and a rigorous diet combined with monoclonal antibodies are the main treatment methods for CPV-2-infected dogs; however, the recovery rates vary from 27.8 to $93.5 \%(39,53,55,56,64,65)$. Both disease and pathology of the infected animal differ

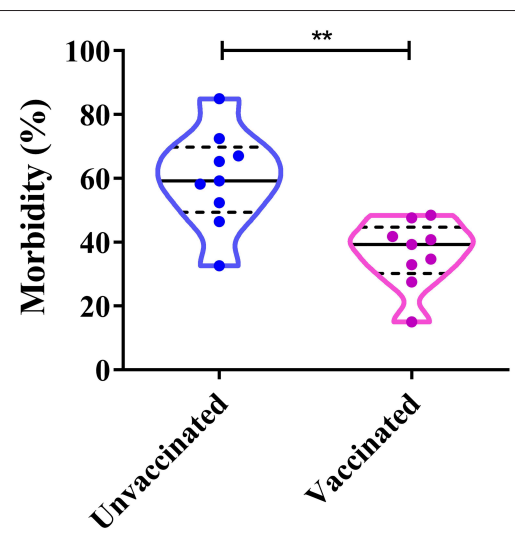

FIGURE 7 | Correlation between dog vaccinations and canine parvovirus (CPV) infection in China. ${ }^{* \star} P<0.05$.

depending on the age. CPV-2 infection in adult dogs results in temporary panleukopenia or lymphopenia; CPV-2 infection in neonatal animals causes myocarditis $(12,66)$. CPV-2 monoclonal antibodies are highly therapeutic in a short period of time and have treatment well effect (53). The cure rate for a CPV2 single infection is higher than that of a coinfection with other viruses (41). With improvements in medical treatments, CPV-2 cure rates have been improved using specific drugs or other treatments.

\section{Coinfection by CPV-2 With Other Pathogens}

The etiology of canine diarrhea is extremely complex because of the frequency of coinfections. In our previous study, we detected and analyzed viruses and bacteria from 201 diarrhea dog feces samples, collected from three cities in Heilongjiang province, Northeast China. We detected CPV-2, CCoV, CaKV, $\mathrm{CBV}$, and CDV, and we also detected diarrheagenic Escherichia coli, Campylobacter spp., Salmonella enterica, Shigella spp., Vibrio cholerae, Vibrio vulnificus, and Yersinia enterocolitica $(60,67-71)$. Of the 201 fecal samples, $11.44 \%(23 / 201)$ were pathogen free and $88.56 \%$ (178/201) were positive for one or more pathogen (virus or bacteria). Among these, CPV-2 only infected $29.85 \%$ (60/201) of samples, whereas coinfection of two-, three-, four-, five-, six-, and seven-pathogen-positive samples accounted for $23.88 \%$ (48/201), 18.41\% (37/201), 9.45\% (19/201), 5.47\% (11/201), $1.00 \%(2 / 201)$, and $0.50 \%(1 / 201)$, respectively (Figure 8A). Of the 201 samples, the CPV-2-positive rate was $47.26 \%(95 / 201)$. The coinfection rates with CPV-2 occurred with the following 11 pathogens: CCoV, CDV, canine bocavirus, CaKV, diarrheagenic E. coli, Campylobacter spp., S. enterica, Shigella spp., V. cholerae, V. vulnificus, and $Y$. enterocolitica, at frequencies of 18.95, 27.37, 7.37, 14.74, 34.74, $8.42,3.16,4.21,37.89,1.05$, and $3.16 \%$, respectively (60, 6771) (Figure 8B). These data indicated that CPV-2 was the main causative agent of canine diarrhea in Northeast China and that coinfection with other pathogens was a common occurrence. Zhao et al. (8) reported that the coinfection rate of CPV$\mathrm{CDV}, \mathrm{CPV}-\mathrm{CCoV}, \mathrm{CPV}$ coccidium (Isospora), CPV hookworm 


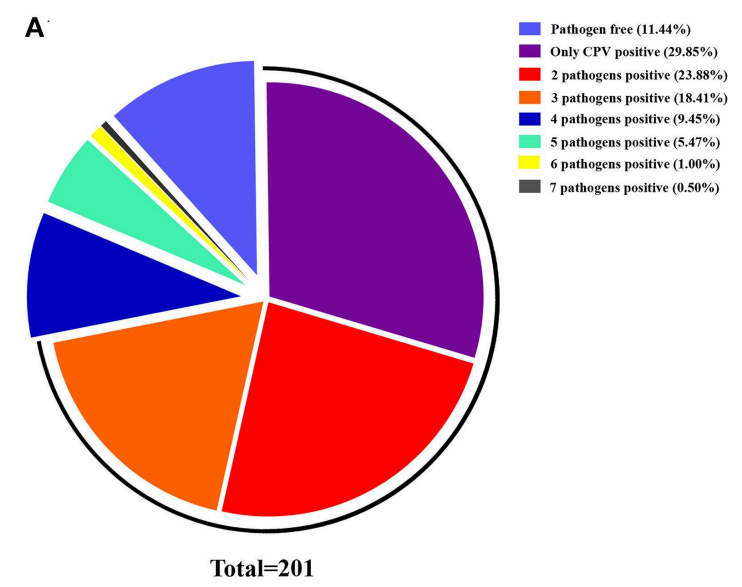

B

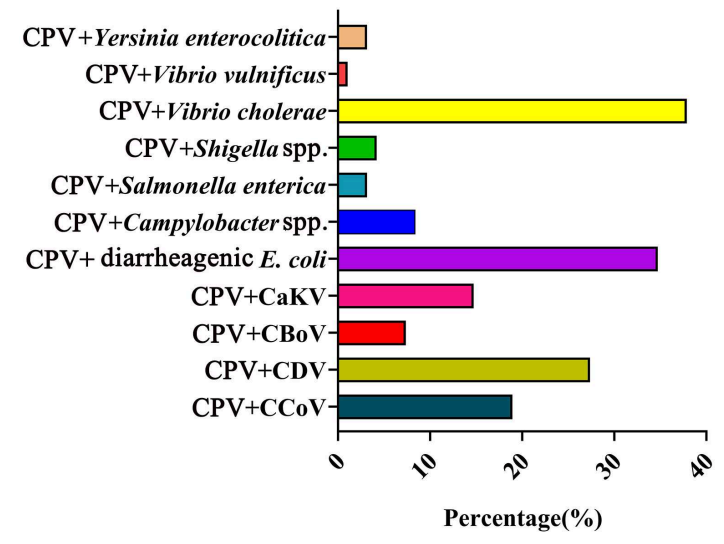

FIGURE 8 | (A) Coinfection analysis of CPV with multiple pathogens. (B) The coinfection rate of CPV with other enteric viruses or bacteria. The data were cited from previously published papers $(60,67-71)$ in our lab.

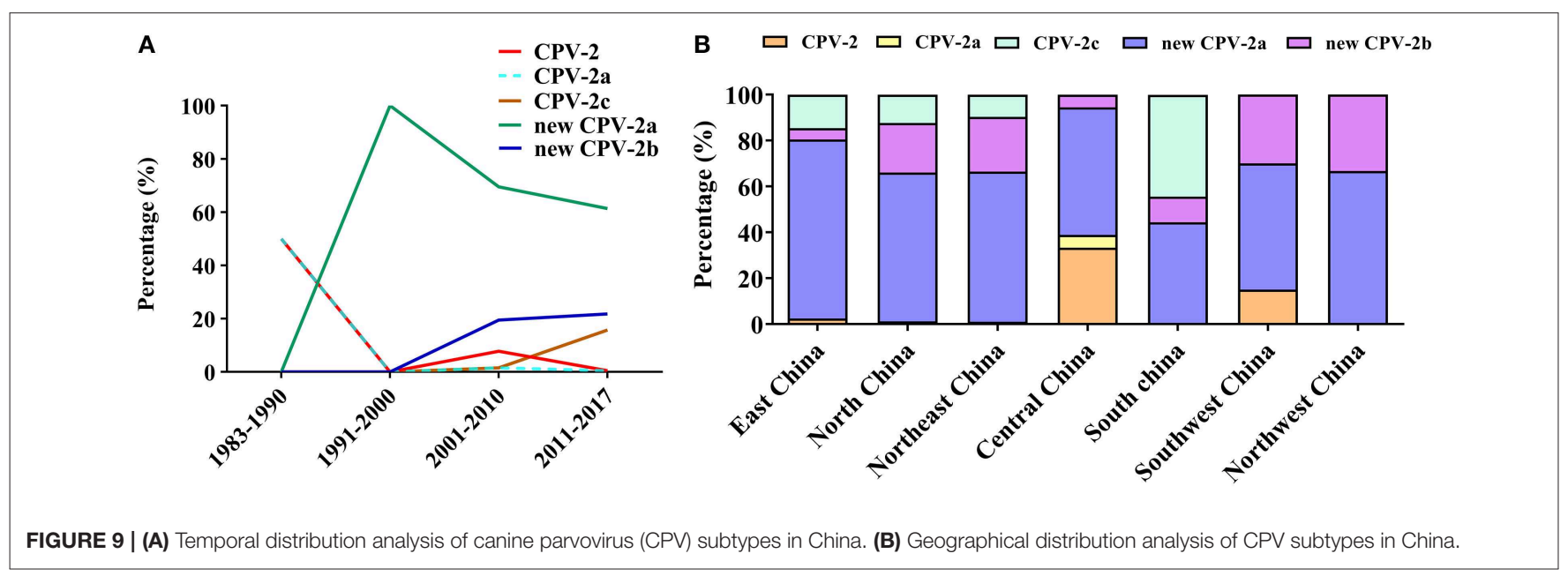

(Ancylostoma), CPV roundworm (Toxocara), CPV tapeworm (Dipylidium), and CPV Babesia spp. was 4.79\% (56/1,169), $1.11 \%(13 / 1,169), 10.00 \%$ (117/1,169), $2.40 \%(28 / 1,169), 1.03 \%$ $(12 / 1,169), 0.17 \%(2 / 1,169)$, and $0.09 \%(1 / 1,169)$, respectively. Detection of the virus was conducted using a CPV, CDV, or $\mathrm{CCoV}$ colloidal gold test strip, respectively; detection of the parasite was conducted by microscopy according to the characteristic of these parasites; and detection of the bacteria was conducted by PCR (8). The coinfection of canine enteric viruses and bacteria frequently occur in diarrheic dogs, both in China and other countries $(26,59,73)$. The potential pathogenic agents were complicated, and there are severe coinfection events of canine diarrhea in China. CPV infection occurs in both unvaccinated and vaccinated dogs (72). In addition, some studies suggested that dogs harboring parasites were especially susceptible to $\mathrm{CPV}$ infection $(74,75)$. The accompanying pathogens that occur with CPV-2 coinfections suggest that they should be considered in vaccination programs to control CPV-2 outbreaks (76).

\section{GENETIC EVOLUTION OF CPV IN CHINA}

\section{Subtyping CPV Strains}

The CPV is undergoing positive selection and has evolved independently in different populations (77), in which genomic substitution rates were similar to those of RNA viruses (66). So far, CPV circulating antigenic variants include CPV-2, CPV2a, CPV-2b, CPV-2c, new CPV-2a, and the new CPV-2b (24). To clarify the evolution of CPV strains in China, we analyzed the geographical and temporal distribution of CPV variants in China collected from GenBank (Figure 9). In the early 1980s, the original CPV-2 started circulating in Chinese canine populations; however, in 1986, CPV-2a replaced CPV-2 as the predominant Chinese isolate (78). The figure has shown that the new CPV-2a has gradually become stable in recent years, while the new CPV$2 \mathrm{~b}$ has increased slowly, and the CPV-2c has shown significant growth trends since 2010 (Figure 9A). In addition, new CPV-2a and CPV-2b strains are distributed over all parts of the country; CPV-2c appears to have circulated in the eastern, northern, northeastern, and southern regions of China. CPV-2 circulated 
in eastern, central, and southwestern regions, whereas CPV-2a circulated only in Central China (Figure 9B). In their work, Zhang et al. (20) indicated that new CPV-2a and CPV-2b strains started circulating in China from the late 1990s onwards and that new CPV-2a has become the predominant CPV type, which is consistent with our data (79) (Figure 9B). The new CPV$2 \mathrm{a}$ and $\mathrm{CPV}-2 \mathrm{~b}$ strains have been cocirculating in Northeast China, which is consistent with previous observations (58). In conclusion, since the first outbreak of CPV-2 in China, the predominant CPV-2 epidemic strains were the new CPV-2a that is cocirculating with the new CPV-2b and CPV-2c. The relative frequencies of these strains appear to differ by geographic regions $(80,81)$. The detailed information of CPV-2 strains used in temporal and geographical distribution analysis was showed in Supplementary Materials.

\section{Phylogenetic Analysis of CPV Strains in China}

The CPV was characterized by strong selection for specific mutations in VP2, the driving forces of which most likely was optimal receptor binding and antigenic escape (82). To further explore the evolution of CPV, the entire VP2 gene sequences of CPV strains were retrieved from the NCBI nucleotide database to construct phylogenetic trees. These nucleotide sequences were

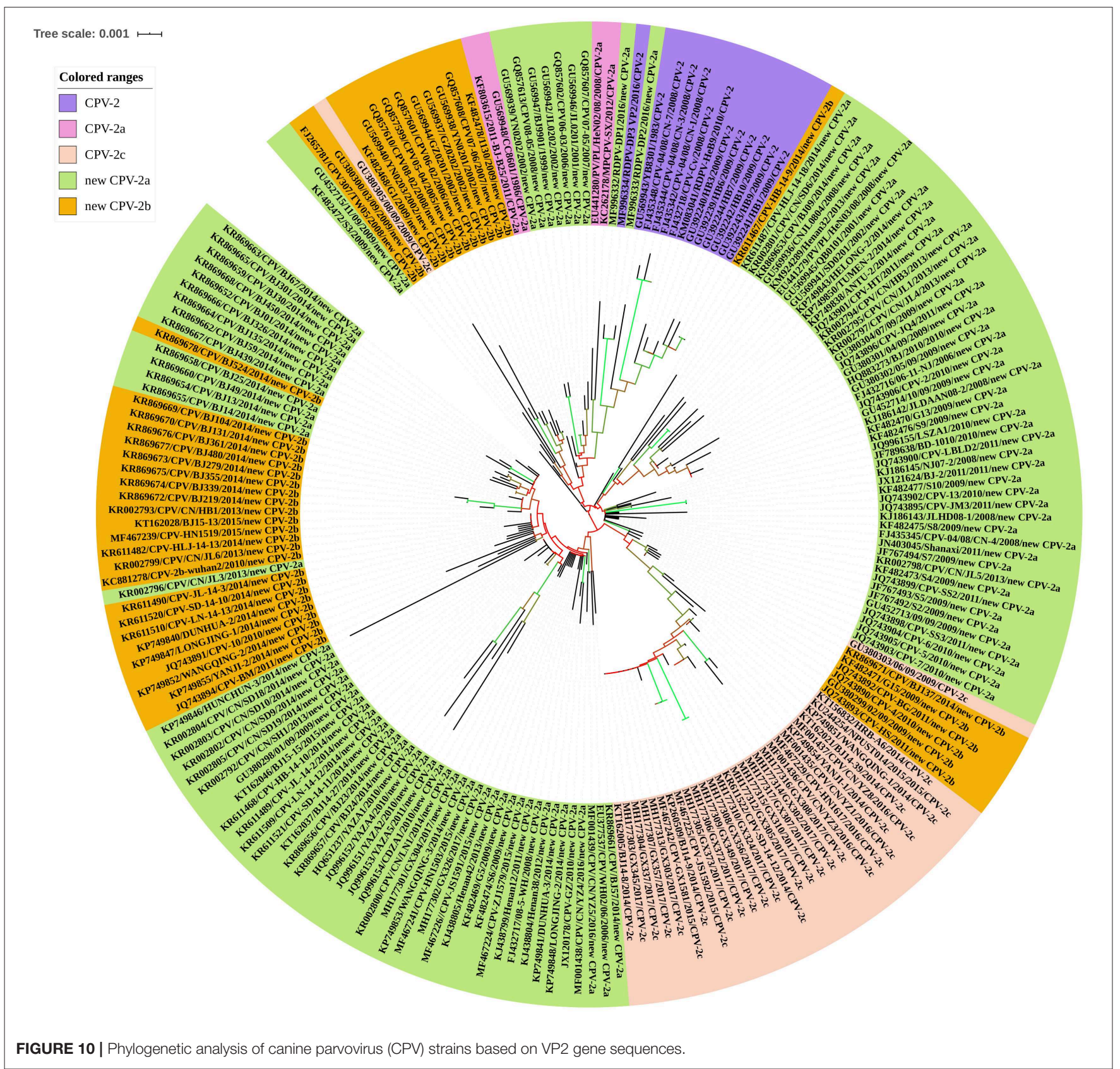


used to generate a neighbor-joining phylogenetic tree using the ClustalX alignment tool in the MEGA6.06 software program (83). Neighbor-joining phylogenetic trees were constructed using the p-distance model, with 1,000 bootstrap replicates, and the remaining default parameters in the MEGA 6.06 software. The phylogenetic tree was annotated with the Interactive Tree of Life (iTOL) software (http://itol.embl.de/), an online tool for the display and annotation of phylogenetic trees (84). A VP2-genebased phylogenetic analysis revealed that the $204 \mathrm{CPV}$ strains clustered into their respective antigenic variants: CPV-2, CPV2a, CPV-2c, new CPV-2a, and new CPV-2b, all circulating in different Chinese provinces or municipalities. In this analysis, the new CPV-2a strains displayed wider distributions and had a greater number. The CPV-2a and CPV-2c strains have been sporadically detected. Interestingly, the new CPV-2b strain was dispersed into the evolutionary topological branches of the new CPV-2a strain (Figure 10). In conclusion, circulating $\mathrm{CPV}$ antigenic variants in China include CPV-2, CPV-2a, CPV-2c, new CPV-2a, and new CPV-2b. A summary of VP2 sequences has provided a comprehensive perspective on $\mathrm{CPV}$ 2 evolution. Going forward, correlative biological studies should be performed.

\section{The Spreading of Global CPV Strains}

The global distribution and temporal dynamics of CPV variants have been extensively studied by analyzing CPV strains from diverse geographic regions and different years $(66,82,85)$. Recent reports indicated that CPV-2a is prevalent mainly in Australia, India, Hungary, Korea, China, and Greece (79, 80, 8689). CPV-2b is the prevalent variant in the United States, the United Kingdom, and Japan, but with different frequencies (3, 24, 90, 91). The CPV-2c is detected mainly in Italy and Argentina, and Uruguay $(24,77,92-95)$. CPV-2 was completely replaced by the CPV-2a variant in America, which is consistent with the prevalence of CPV in China $(96,97)$. CPV-2c has reached considerable frequencies in some countries of the America and Europe, which is similar to the prevalence in China $(17,77,93$, 94, 98, 99). Pérez reported that the CPV-2c was the only variant detected in the Uruguayan dog population from 2007 to 2009. However, CPV-2a with a relatively high prevalence replacing an established CPV-2c in 2010 (94). Interestingly, similar studies indicated that the CPV-2a was introduced to South America, which was associated with strengthening of connections between China and Uruguay (100). The migrations of CPV are likely spread among countries in close geographic proximity through the movement of infected animals or mechanical vectors (82).

\section{REFERENCES}

1. Kelly WR. An enteric disease of dogs reselmbing feline panleucopaenia. Aust Vet J. (1978) 54:593. doi: 10.1111/j.1751-0813.1978.tb02426.x

2. Appel MJ, Cooper BJ, Greisen H, Scott F, Carmichael LE. Canine viral enteritis. I. Status report on corona- and parvo-like viral enteritides. Cornell Vet. (1979) 69:123-133.

3. Decaro N, Buonavoglia C. Canine parvovirus-a review of epidemiological and diagnostic aspects, with emphasis on type 2c. Vet Microbiol. (2012) 155:1-12. doi: 10.1016/j.vetmic.2011.09.007
Nevertheless, CPV-2a, 2b, and $2 \mathrm{c}$ are circulating in almost equal proportions in Tunisia (101). CPV-2a, CPV-2b, and CPV-2c are currently spreading globally, and their relative frequencies may be related to the geographic region and time of the sample collection and different commercial flows of dogs imported from foreign countries $(3,77)$

\section{PROSPECTS}

In conclusion, we have summarized novel epidemiological information for CPV infections in China, including the origin, prevalence, and genetic evolution of the virus. This mini-review will facilitate an increased comprehension of CPV strains in China. Tracing virus mutations, developing effective vaccines, enhancing quarantine measures, and developing antibodies against CPV-2 antigenic variants will provide effective measures in preventing and controlling CPV-2 infections in the future. Furthermore, pathogenicity differences between different CPV2 antigenic variants, and the cross-protection effects of existing commercial vaccines against CPV-2 are the important problems that require attention.

\section{AUTHOR CONTRIBUTIONS}

DS conceived the study. SQ, DG, and JZ analyzed the data. DS and SQ wrote the manuscript.

\section{FUNDING}

This work was supported by the Outstanding Youth Science Foundation of Heilongjiang province in China (grant no. JC2017007), the Heilongjiang Province Postdoctoral Science Foundation of China (LBH-Q16188), Heilongjiang Bayi Agricultural University Support Program for San Heng San Zong (TDJH201804), Graduate innovative research projects in Heilongjiang Bayi Agricultural University (YJSCX2018-Z02), the Central Public-interest Scientific Institution Basal Research Fund (No. Y2019XK02), and the State Key Laboratory of Veterinary Etiological Biology (SKLVEB2018KFKT014).

\section{SUPPLEMENTARY MATERIAL}

The Supplementary Material for this article can be found online at: https://www.frontiersin.org/articles/10.3389/fvets. 2020.00005/full\#supplementary-material
4. Yi L, Tong M, Cheng Y, Song W, Cheng S. Phylogenetic analysis of canine parvovirus VP2 gene in China. Transbound Emerg Dis. (2016) 63:e2629. doi: 10.1111/tbed.12268

5. Zhou P, Zeng W, Zhang X, Li S. The genetic evolution of canine parvovirus-A new perspective. PLoS ONE. (2017) 12:e0175035. doi: 10.1371/journal.pone.01 75035 .

6. Nandi S, Chidri S, Kumar M, Chauhan R. Occurrence of canine parvovirus type $2 c$ in the dogs with haemorrhagic enteritis in India. Res Vet Sci. (2010) 88:169-171. doi: 10.1016/j.rvsc.2009.05.018 
7. Zhou L, Tang Q, Shi L, Kong M, Liang L, Mao Q, et al. Full-length genomic characterization and molecular evolution of canine parvovirus in China. Virus Genes. (2016) 52:411-6. doi: 10.1007/s11262-016-1309-y

8. Zhao Z, Liu H, Ding K, Peng C, Xue Q, Yu Z, et al. Occurrence of canine parvovirus in dogs from Henan province of China in 2009-2014. BMC Vet Res. (2016) 12:138. doi: 10.1186/s12917-016-0753-1

9. Zhao H, Wang J, Jiang $\mathrm{Y}$, Cheng $\mathrm{Y}$, Lin $\mathrm{P}$, Zhu H, et al. Typing of canine parvovirus strains circulating in North-East China. Transbound Emerg Dis. (2017) 64:495-503. doi: 10.1111/tbed.12390.

10. Nelson DT. Eustis SL, McAdaragh JP, Stotz I. Lesions of spontaneous canine viral enteritis. Vet Pathol. (1979) 16:680-6. doi: $10.1177 / 030098587901600606$

11. Carman PS, Povey RC. Pathogenesis of canine parvovirus-2 in dogs: haematology, serology and virus recovery. Res Vet Sci. (1985) 38:13440. doi: 10.1016/S0034-5288(18)31816-2

12. Parrish CR. Pathogenesis of feline panleukopenia virus and canine parvovirus. Baillieres Clin Haematol. (1995) 8:5771. doi: 10.1016/S0950-3536(05)80232-X

13. Pratelli A, Buonavoglia D, Tempesta M, Guarda F, Carmichael L, Buonavoglia C. Fatal canine parvovirus type-1 infection in pups from Italy. $J$ Vet Diagn Invest. (1999) 11:365-7. doi: 10.1177/104063879901100413

14. Reed AP, Elaine VJ, Timothy JM. Nucleotide sequence and genome organization of canine parvovirus. J Virol. (1988) 62:266-76.

15. Strassheim ML, Gruenberg A, Veijalainen P, Sgro JY, Parrish CR. Two dominant neutralizing antigenic determinants of canine parvovirus are found on the threefold spike of the virus capsid. Virology. (1994) 198:17584. doi: 10.1006/viro.1994.1020

16. Nelson CDS, Palermo LM, Hafenstein SL, Parrish CR. Different mechanisms of antibody-mediated neutralization of parvoviruses revealed using the Fab fragments of monoclonal antibodies. Virology. (2007) 361:28393. doi: $10.1016 /$ j.virol.2006.11.032

17. Pinto LD, Streck AF, Gonçalves KR, Souza CK, Corbellini ÂO, Corbellini LG, et al. Typing of canine parvovirus strains circulating in Brazil between 2008 and 2010. Virus Res. (2012) 165:29-33. doi: 10.1016/j.virusres.2012.01.001

18. Zhang GT, Zhang YY. Diagnosis and prevention and control of canine parvovirus disease. Modern Anim Husbandry Sci Technol. (2017) 131. doi: 10.19369/j.cnki.2095-9737.2017.04.122

19. Li J, Li Z, Wang YH, Cheng X. Epidemiological investigation of canine parvovirus disease in Beijing City and surrounding areas during 2016-2017. China Anim Health. (2018) 20:51-3. doi: $10.3969 /$ j.issn.1008-4754.2018.08.025

20. Zhang Q, Xu XM, Zhai GQ, Wang Z, Hou SH. Molecular characterization of canine parvovirus strains circulating in China. Afr J Biotechnol. (2009) 9:4556-60. doi: 10.5897/AJB10.055

21. Mittal M, Chakravarti S, Mohapatra JK, Chug PK, Dubey R, Upmanuyu V, et al. Molecular typing of canine parvovirus strains circulating from 2008 to 2012 in an organized kennel in India reveals the possibility of vaccination failure. Infect Genet Evol. (2014) 23:1-6. doi: 10.1016/j.meegid.2014.01.015

22. Martella V, Cavalli A, Decaro N, Elia G, Desario C, Campolo $\mathrm{M}$, et al. Immunogenicity of an intranasally administered modified live canine parvovirus type $2 \mathrm{~b}$ vaccine in pups with maternally derived antibodies. Clin Diagn Lab Immunol. (2005) 12:1243-5. doi: 10.1128/CDLI.12.10.1243-1245.2005

23. Hu JJ, Zhang XY, Han SZ, Zhao JZ, Tian ZH. A survey of diagnosis and treatment of pet canine parvovirus disease in China. J Anim Vet Adv. (2011) 10:2058-60. doi: 10.3923/javaa.2011.2058.2060

24. Miranda C, Thompson G. Canine parvovirus: the worldwide occurrence of antigenic variants. J Gen Virol. (2016) 97:20432057. doi: 10.1099/jgv.0.000540

25. Li X, Wu H, Wang L, Spibey N, Liu C, Ding H, et al. Genetic characterization of parvoviruses in domestic cats in Henan province, China. Transbound Emerg Dis. (2018) 65:1429-1435. doi: 10.1111/tbed.13014

26. Filipov C, Decaro N, Desario C, Amorisco F, Sciarretta R, Buonavoglia C. Canine parvovirus epidemiology in Bulgaria. J Vet Diagn Invest. (2011) 23:152-154. doi: 10.1177/104063871102300129

27. Hoang M, Lin WH, Le VP, Nga BTT, Chiou MT, Lin CN. Molecular epidemiology of canine parvovirus type 2 in Vietnam from November 2016 to February 2018. Virol J. (2019) 16:52. doi: 10.1186/s12985-019-1159-z
28. Carmichael LE, Binn LN. New enteric viruses in the dog. Adv Vet Sci Comp Med. (1981) 25:1-37.

29. Xu HK, J H, Guo B, Lai J. Epidemiology and clinical pathology observation of a canine viral enteritis outbreak in canine population. Anim Husbandry Vet Med. (1983) 5:197-9.

30. Liang SZ, Wei XR, Fan WG, Wang ZS, Li YZ, Wu SF, et al. Research on the canine transmissible gastroenteritis. Shanghai J Anim Husbandry Vet Med. (1982) 2:172-5.

31. Jia BN, X XZ, Wu Y, Liu L, Zhu W, Zhang J. Obeservation of canine parvovirus under electron microscope and immunoelectron microscope. $J$ Livestock Infect Dis. (1983) 4:11-3.

32. Zhu WZ, Zhang JH, Jia BN. Preliminary research on pathogen of canine hemorrhagic enteritis. Bull Vet Coll PLA. (1983) 3:24-9. doi: 10.16303 /j.cnki.1005-4545.1983.01.005

33. Chen AS, Sa Y, Lu BK, He JY, Li CX. Diagnosis investigation and control of canine parvovirus enteritis pathogen. Chin J Vet Med. (1986) 12:2-5.

34. He SH, Li B, Liu YF. Serum epidemiological investigation of canine parvovirus infection. Jiangxi J Anim Husbandry Vet Med. (1987) 3:28-30.

35. Xia XZ, Y JH, Fan QS, Yin Z, Wu YL, Cheng H, et al. Research on attenuated vaccine of canine parvovirus enteritis. Bull Vet Coll PLA. (1989) 9:325-30. doi: 10.16303/j.cnki.1005-4545.1989.04.002

36. Guo B. Serology and electron microscope diagnosis of canine parvovirus enteritis. Yunnan J Anim Sci Vet Med. (1986) 3:4-6.

37. Guo B, Yang RH, Yang HX. Serum epidemiological investigation of canine parvovirus in Southwest and south China. (1987) 3:18-20. doi: 10.16656/j.issn.1673-4696.1987.03.007

38. Gao Y, Wang YY, Zhao BR. Epidemiological investigation and diagnosis and treatment of canine parvovirus. Kennel Technol. (1997) 8:24-5.

39. Wan YL. Investigation of canine parvovirus infection in pet hospital of Tianjin. J Tradit Chin Vet Med. (2011) 13:4852. doi: 10.13823/j.cnki.jtcvm.2011.04.016

40. Peng CP, Ding K, Zhao ZQ, Xue Y, Zhou BH, Duan XX, et al. Epidemiological investigation of canine parvovirus in Luoyang area. J Henan Agric Sci. (2014) 84:2903-11. doi: 10.1210/jcem.84.8.5908

41. Zhuo GR, Di HS, Lu W, Liu JD, Zhang H, Wang CF. Epidemiological investigation and treatment effect of canine parvovirus disease in Taizhou, Jiangsu province. Jiangsu Agric Sci. (2015) 43:216-9. doi: 10.15889/j.issn.1002-1302.2015.05.072

42. Zhao ZQ, Liu HS, Peng CP, Long T, Chang SK, Ding K, et al. Epidemiological investigation of canine parvovirus disease in dogs in Henan area from 2009 to 2014. Chin J Prevent Vet Med. (2016) 38:4537. doi: $10.3969 /$ j.issn.1008-0453.2016.06.07

43. Cao L, Zhang JM, Gao LY. Epidemiological investigation of canine parvovirus diseased Dogs in Jiuquan City. J Anim Sci Vet Med. (2017) 36:91-3. doi: 10.3969/j.issn.1004-6704.2017.06.033

44. Yu XQ, Wen DL, Zhang ZH, Qu PW, Chen L, Qu WX, et al. Epidemiological investigation of canine parvovirus disease in Pudong City. Shanghai J Anim Husbandry Vet Med. (2017) 44-5. doi: 10.14170/j.cnki.cn31-1278/s.2017. 02.017

45. Wang XB, Ji XQ, Long DD. Epidemiological investigation of canine parvovirus in Zunyi City. Guizhou J Anim Husbandry Vet Med. (2018) 42:42-4. doi: 10.3969/j.issn.1007-1474.2018. 04.014

46. Wu FS, Yuan KC, Wang QF. Investigation and analysis on canine parvovirus in Shanghai. Modern Anim Husbandry. (2018) 2:50-2. doi: 10.3969/j.issn.1008-3111.2018.02.014

47. Jing SY, Zhao QX, Song SB, Li WS. Epidemiology survey and analysis of canine parvovirus disease in Lanzhou City. J Anim Sci Vet Med. (2018) 37:60-5. doi: 10.3969/j.issn.1004-6704.2018.02.019

48. Ye JH, Ma CS, Xu YS. Serological investigation of canine parvovirus disease. Kennel Technol. (1997) 8:7-9.

49. Wang XZ, Zhang LC, Shen DG, Cai JS. Serological investigation of canine parvovirus disease in stray dogs in Yushu City. Chin J Vet Med. (2014) 50:67. doi: 10.3969/j.issn.0529-6005.2014.07.024

50. Hao JF, Yuan QW, Ning LC, Zhang C, Wang L, Zhao Q. Epidemiological investigation and analysis of canine parvovirus disease. China Anim Husbandry Vet Med. (2012) 39:2113. doi: $10.3969 / j . i s s n .1671-7236.2012 .03 .048$ 
51. Liu J, Zhao XG, Lu J, Zhen XL, Yuan WF. Epidemiological investigation of canine parvovirus disease. China Anim Husbandry Vet Med. (2013) 40:199-201. doi: 10.3969/j.issn.1671-7236.2013.03.045

52. Kang YL. Epidemiological investigation of canine parvovirus disease in Qingdao City. Shandong J Anim Sci Vet Med. (2016) 37:401. doi: $10.3969 /$ j.issn.1007-1733.2016.03.029

53. Xu GM, Cao SF, Che YG, Wu MQ. Analysis of the incidence and treatment of 245 ceases of canine parvovirus disease. Anim Husbandry Vet Med. (2017) 49:117-9.

54. Li J, Li Z, Wang YH, Cheng X. Diagnosis and comprehensive prevention of canine parvovirus disease. Modern Anim Husbandry Sci Technol. (2018) 44:118. doi: 10.19369/j.cnki.2095-9737.2018.08.106

55. Chen YK, Xing YJ, Song XD, Hu Y, Song DL. Epidemiological investigation and prevention of 224 ceases of canine parvovirus infection. Heilongjiang Anim Sci Vet Med. (2008) 4:84-6. doi: 10.13881/j.cnki.hljxmsy.2008.04.038

56. Sun $\mathrm{M}, \mathrm{Wu} \mathrm{JH}$. Investigation of epidemiology, prevention and treatment on canine parvovirus disease in Changji of Xinjiang. Prog Vet Med. (2014) 35:163-6. doi: 10.16437/j.cnki.1007-5038.2014.06.026

57. Gao Y, Wang YY, Zhao BR. Epidemiological investigation and diagnosis and treatment of canine parvovirus. Kennel Technol. (1997) 8:24-5.

58. Huang XH, Wang P, Liu LK, Ma L, Fang XF, Zhao B, et al. Epidemiological investigation of canine parvovirus disease in Nanning City. Guangxi J Anim Husbandry Vet Med. (2018) 34:76-9. doi: 10.3969/j.issn.1002-5235.2018.02.006

59. Cavalli A, Desario C, Kusi I, Mari V, Lorusso E, Cirone F, et al. Detection and genetic characterization of canine parvovirus and canine coronavirus strains circulating in district of Tirana in Albania. J Vet Diagn Invest. (2014) 26:563-6. doi: 10.1177/1040638714538965

60. Geng YF, Guo DH, Li CQ, Wang EY, Wei S, Wang ZH, et al. Co-circulation of the rare CPV-2c with unique Gln370Arg substitution, New CPV-2b with unique Thr440Ala substitution, and new CPV-2a with high prevalence and variation in Heilongjiang Province, Northeast China. PLoS ONE. (2015) 10:e0137288. doi: 10.1371/journal.pone. 0137288

61. Pollock RV, Carmichael LE. Maternally derived immunity to canine parvovirus infection: transfer, decline, and interference with vaccination. $J$ Am Vet Med Assoc. (1982) 180:37-42.

62. Waner T, Naveh A, Wudovsky I, Carmichael LE. Assessment of maternal antibody decay and response to canine parvovirus vaccination using a clinic-based enzyme-linked immunosorbent assay. J Vet Diagn Invest. (1996) 8:427-32. doi: $10.1177 / 104063879600800404$

63. Kitala P, McDermott J, Kyule M, Gathuma J, Perry B, Wandeler A. Dog ecology and demography information to support the planning of rabies control in Machakos District, Kenya. Acta Trop. (2001) 78:21730. doi: 10.1016/S0001-706X(01)00082-1

64. Chen SM, Xia XZ, Chen H. Therapeutic effect observation of soup of dog diarrhea on experimental canine parvovirus enteritis. Chin J Vet Sci. (1984) 4:115-9. doi: 10.16303/j.cnki.1005-4545.1984.02.004

65. Zheng XD, Song JC. Investigation and prevention of canine parvovirus disease. Kennel Technol. (1998) 9:13-5.

66. Shackelton LA, Parrish CR, Truyen U, Holmes EC. High rate of viral evolution associated with the emergence of carnivore parvovirus. Proc Natl Acad Sci USA. (2005) 11:379-84. doi: 10.1073/pnas.04067 65102

67. Guo DH, Wang ZH, Yao S, Li CQ, Geng YF, Wang EY, et al. Epidemiological investigation reveals genetic diversity and high co-infection rate of canine bocavirus strains circulating in Heilongiiang province, Northeast China. Res Vet Sci. (2016) 106:7-13. doi: 10.1016/j.rvsc.2016.03.003

68. Li CQ, Wei S, Guo DH, Wang ZH, Geng YF, Wang EY, et al. Prevalence and phylogenetic analysis of canine kobuviruses in diarrhoetic dogs in northeast China. J Vet Med Sci. (2016) 78:7-11. doi: 10.1292/jvms.15-0414

69. Wang EY, Guo DH, Li CQ, Wei S, Wang ZH, Liu QJ, et al. Molecular characterization of the ORF3 and $\mathrm{S} 1$ genes of porcine epidemic diarrhea virus non S-INDEL strains in seven regions of China, 2015. PLoS ONE. (2016) 11:e0160561. doi: 10.1371/journal.pone.0160561

70. Wang XY, Li CQ, Guo DH, Wang XY, Wei S, Geng YF, et al. Cocirculation of canine coronavirus I and IIa/b with high prevalence and genetic diversity in Heilongjiang Province, Northeast China. PLoS ONE. (2016) 11:e0146975. doi: 10.1371/journal.pone.0146975
71. Li CQ, Guo DH, Wu R, Kong FZ, Zhai JJ, Yuan DW, et al. Molecular surveillance of canine distemper virus in diarrhoetic puppies in northeast China from May 2014 to April 2015. J Vet Med Sci. (2018) 80:102933. doi: 10.1292/jvms.17-0559

72. Wang J, Lin $\mathrm{P}$, Zhao $\mathrm{H}$, Cheng $\mathrm{Y}$, Jiang $\mathrm{Z}$, Zhu $\mathrm{H}$, et al. Continuing evolution of canine parvovirus in China: isolation of novel variants with an Ala5Gly mutation in the VP2 protein. Infect Genet Evol. (2015) 38:73-8. doi: 10.1016/j.meegid.2015.12.009

73. Acosta-Jamett G, Surot D, Cortés M, Marambio V, Valenzuela C, Vallverdu A, et al. Epidemiology of canine distemper and canine parvovirus in domestic dogs in urban and rural areas of the Araucanía region in Chile. Vet Microbiol. (2015) 178:260-4. doi: 10.1016/j.vetmic.2015.05.012

74. Luo HQ, Song XZ, Wang QY, Duan LC. Epidemiological investigation of canine parvovirus disease in small animal hospital in Wenzhou area. Acta Agric Zhejiangensis. (2014) 26:887-91. doi: 10.3969/j.issn.1004-1524.2014.04.09

75. Grellet A, Brunopolack, Feugier A, Boucraut-Baralon C, Grandjean D, Vandewynckel L, et al. Prevalence, risk factors of infection and molecular characterization of trichomonads in puppies from French breeding kennels. Vet Parasitol. (2013) 197:418-26. doi: 10.1016/j.vetpar.2013.07.030

76. Park SA, Park SY, Song CS, Choi IS, Kim HY, Lee JB, et al. Development of a novel vaccine against canine parvovirus infection with a clinical isolate of the type 2b strain. Clin Exp Vaccine Res. (2012) 1:706. doi: 10.7774/cevr.2012.1.1.70

77. Decaro N, Desario C, Addie DD, Martella V, Vieira MJ, Elia G, et al. The study molecular epidemiology of canine parvovirus. Europe. Emerg Infect Dis. (2007) 13:1222-4. doi: 10.3201/eid1308.070505

78. Xie ZJ, Xia XZ, Hu RL, Zhao ZP, Gao YW, Huang G. Survey of subtypes of CPV isolates in China. Chin J Vet Sci. (2004) 24:421-4. doi: 10.16303/j.cnki.1005-4545.2004.05.003

79. Zhang R, Yang S, Zhang W, Zhang T, Xie Z, Feng H, et al. Phylogenetic analysis of the VP2 gene of canine parvoviruses circulating in China. Virus Genes. (2010) 40:397-402. doi: 10.1007/s11262-010-0466-7

80. Chinchkar SR, Mohana SB, Hanumantha RN, Rangarajan PN, Thiagarajan D, Srinivasan VA. Analysis of VP2 gene sequences of canine parvovirus isolates in India. Arch Virol. (2006) 151:1881-7. doi: 10.1007/s00705-006-0753-8

81. Hoelzer K, Parrish CR. The emergence of parvoviruses of carnivores. Vet Res. (2010) 41:39. doi: 10.1051/vetres/2010011

82. Hoelzer K, Shackelton LA, Parrish CR, Holmes EC. Phylogenetic analysis reveals the emergence, evolution and dispersal of carnivore parvoviruses. $J$ Gen Virol. (2008) 89:2280-9. doi: 10.1099/vir.0.2008/002055-0

83. Tamura K, Stecher G, Peterson D, Filipski A, Kumar S. MEGA6: molecular evolutionary genetics analysis version 6.0. Mol Biol Evol. (2013) 30:27259. doi: 10.1093/molbev/mst197

84. Letunic I, Bork P. Interactive Tree Of Life (iTOL): an online tool for phylogenetic tree display and annotation. Bioinformatics. (2007) 23:1278. doi: 10.1093/bioinformatics/btl529

85. Decaro N, Desario C, Parisi A, Martella V, Lorusso A, Miccolupo A, et al. Genetic analysis of canine parvovirus type 2c. Virology. (2009) 385:510. doi: 10.1016/j.virol.2008.12.016

86. Meers J, Kyaw-Tanner M Bensink Z, Zwijnenberg R. Genetic analysis of canine parvovirus from dogs in Australia. Aust Vet J. (2007) 85:3926. doi: $10.1111 / j .1751-0813.2007 .00206 . x$

87. Ntafis V, Xylouri E, Kalli I, Desario C, Mari V, Decaro N, et al. Characterization of Canine parvovirus 2 variants circulating in Greece. J Vet Diagn Invest. (2010) 22:737-40. doi: 10.1177/104063871002200512

88. Yoon SH, Jeong W, Kim HJ, An DJ. Molecular insights into the phylogeny of canine parvovirus 2 (CPV-2) with emphasis on Korean isolates: a Bayesian approach. Arch Virol. (2009) 154:1353-60. doi: 10.1007/s00705-009-0444-3

89. Demeter Z, Palade EA, Soós T, Farsang A, Jakab C, Rusvai M. Misleading results of the MboII-based identification of type $2 \mathrm{a}$ canine parvovirus strains from Hungary reacting as type 2c strains. Virus Genes. (2010) 41:3742. doi: $10.1007 / \mathrm{s} 11262-010-0478-3$

90. Kapil S, Cooper E, Lamm C, Murray B, Rezabek G, Johnston L, et al. Canine parvovirus types $2 \mathrm{c}$ and $2 \mathrm{~b}$ circulating in North American dogs in 2006 and 2007. J Clin Microbiol. (2007) 45:4044-7. doi: 10.1128/JCM. 01300-07 
91. Hong C, Decaro N, Desario C, Tanner P, Pardo MC, Sanchez S, et al. Occurrence of canine parvovirus type $2 \mathrm{c}$ in the United States. J Vet Diagn Invest. (2007) 19:535-9. doi: 10.1177/104063870701900512

92. Buonavoglia CV, Martella V, Pratelli A, Tempesta M, Cavalli A, Buonavoglia D, et al. Evidence for evolution of canine parvovirus type 2 in Italy. $J$ Gen Virol. (2001) 82:3021-5. doi: 10.1099/0022-1317-82-12-3021

93. Calderón MG, Romanuttia C, D' Antuonoa A, Kellerb L, Mattiona $\mathrm{N}$, LaTorre J. Evolution of canine parvovirus in Argentina between years 2003 and 2010: CPV2c has become the predominant variant affecting the domestic dog population. Virus Res. (2011) 157:10610. doi: 10.1016/j.virusres.2011.02.015

94. Pérez R, Francia L, Romero V, Maya L, Lopez I, Hernandez M. First detection of canine parvovirus type $2 \mathrm{c}$ in South America. Vet Microbiol. (2007) 124:147-52. doi: 10.1016/j.vetmic.2007.04.028

95. Aldaz J, García-Díaz J, Calleros L, Sosa K, Iraola G, Marandino A, et al. High local genetic diversity of canine parvovirus from Ecuador. Vet Microbiol. (2013) 166:214-9. doi: 10.1016/j.vetmic.2013.06.012

96. Parrish CR, O'Connell PH, Evermann JF, Carmichael LE. Natural variation of canine parvovirus. Science. (1985) 230:1046-8. doi: 10.1126/science.4059921

97. Truyen U, Evermann JF, Vieler E, Parrish CR. Evolution of canine parvovirus involved loss and gain of feline host range. Virology. (1996) 215:1869. doi: 10.1006/viro.1996.0021

98. Decaro N, Desario C, Amorisco F, Losurdo M, Colaianni ML, Greco $\mathrm{MF}$, et al. Canine parvovirus type $2 \mathrm{c}$ infectionin a kitten associated with intracranial abscess and convulsions. J Feline Med Surg. (2011) 13:2316. doi: 10.1016/j.jfms.2010.11.012

99. Decaro N, Desario C, Amorisco F, Losurdo M, Elia G, Parisi A, et al. Detection of a canine parvovirus type $2 \mathrm{c}$ with a non-coding mutation and its implications for molecular characterisation. Vet. J. (2013) 196:5557. doi: $10.1016 /$ j.tvjl.2012.12.017

100. Grecco S, Iraola G, Decaro N, Alfieri A, Alfieri A, Gallo Calderón M, et al. Inter-and intracontinental migrations and local differentiation have shaped the contemporary epidemiological landscape of canine parvovirus in South America. Virus Evol. (2018) 9:vey011. doi: 10.1093/ve/vey011

101. Touihri L, Bouzid I, Daoud R, Desario C, El Goulli AF, Decaro N, et al. Molecular characterization of canine parvovirus- 2 variants circulating in Tunisia. Virus Genes. (2009) 38:249-58. doi: 10.1007/s11262-008-0314-1

Conflict of Interest: The authors declare that the research was conducted in the absence of any commercial or financial relationships that could be construed as a potential conflict of interest.

Copyright $\odot 2020$ Qi, Zhao, Guo and Sun. This is an open-access article distributed under the terms of the Creative Commons Attribution License (CC BY). The use, distribution or reproduction in other forums is permitted, provided the original author(s) and the copyright owner(s) are credited and that the original publication in this journal is cited, in accordance with accepted academic practice. No use, distribution or reproduction is permitted which does not comply with these terms. 